* Doutor em Direito das Relações Sociais (PUC-SP). Docente do Programa de Mestrado da Universidade de Marília. Docente do Curso de Graduação em Direito da Universidade Estadual de Londrina. Advogado. E-mail: lourival.oliveira40@ hotmail.com

** Graduanda em Direito na Universidade Estadual de Londrina

E-mail: tsalmeida92@gmail. com

\section{A Precarização do Trabalho Docente: Análise Crítica das Alterações no Ambiente de Trabalho Produzidas no Ensino Superior a Distância}

The Precariousness of the Professor's Work: Critical Analysis of the Changes in the Workplace Produced in Higher Education Distance

\section{Lourival José de Oliveira* Tamires Souza de Almeida**}

Como citar: OLIVEIRA, Lourival José de; ALMEIDA, Tamires Souza de. A precarização do trabalho docente: análise crítica das alterações no ambiente de trabalho produzidas no ensino superior a distância. Revista do Direito Público, Londrina, v. 13, n. 3, p. 10-23, dez. 2018. DOI: 10.5433/24157-108104-1.2018v13n3 p. 10. ISSN: $1980-511 \mathrm{X}$

Resumo: A presente pesquisa aborda, utilizando-se do método dedutivo e como meio de pesquisa o levantamento bibliográfico, a precarização do trabalho docente no ensino superior a distância no Brasil, acarretada, principalmente, pelas mudanças no seu ambiente de trabalho produzidas em parte pelo emprego de novas tecnologias. A não regulamentação dessa forma específica do trabalho justifica o seu estudo, sendo que o emprego das novas tecnologias inseridas nesse meio laboral trouxe consequências danosas, podendo ser afirmado que ocorreram grandes mudanças na maneira da prestação do trabalho. Conclui-se que o trabalho do professor no ensino superior a distância encontra-se em processo de desumanização, carecendo de uma regulamentação específica que seja suficiente para preservar a dignidade humana. Enquanto isso não acontece, as decisões judiciais sobre a matéria deverão buscar, nos princípios norteadores do Direito do Trabalho e do Direito Ambiental do Trabalho, os parâmetros de proteção ao trabalho docente inserido nesse processo.

Palavras-chave: Ambiente de trabalho. Ensino a distância. Precarização. Trabalho docente.

Abstract: This paper utilized the deductive method as a means 
for researching the precariousness of a professor's workplace as long-distance learning is modifying Brazil's colleges. This paradigm shift in the workplace is a direct result of advancements in new technologies. Furthermore, there are non-existent legal regulations for this specific form of work as analyzed by this study. Moreover, the use of new technologies embedded in the workplace can create harmful consequences, as major changes in the workplace is directly associated with employees' work performance. This paper concludes that professors in longdistance learning are suffering a process of dehumanization, as there lacks specific rules sufficient to preserve human dignity. In the meantime, judicial decisions should, with the guiding principles of labor law and environmental Law, protect those most vulnerable in this process.

Keywords: Education distance. Precariousness. Professor's work. Work environment. 


\section{INTRODUÇÃO}

As mudanças ocorridas no ambiente de trabalho do docente, em face do emprego das novas tecnologias de informação e comunicação, trouxeram consequências significativas a essa categoria de trabalhador, principalmente no que tange ao docente da modalidade de ensino a distância, modalidade essa que tem cada vez mais adesão das instituições de ensino superior.

Esse tema merece atenção especial, pois não há tratamento específico e adequado na legislação brasileira protegendo o docente que leciona a distância bem como em seu ambiente laboral, sendo que a regulamentação da prestação dessa modalidade de trabalho está limitada ao contrato firmado entre empregado e empregador.

Dessa maneira, pretende-se demonstrar a necessidade de tal regulamentação devido à precarização acarretada pelo uso nocivo das novas tecnologias inseridas em seu meio ambiente de trabalho. Não quer dizer que apenas nessa modalidade de trabalho esteja ocorrendo a erosão das principais formas de proteção social. Aqui, destaca-se uma extrema extração de lucro em desacordo com a retribuição destinada ao prestador de serviço.

Para tal demonstração, a presente pesquisa apresentará os procedimentos na execução dessa modalidade de trabalho e consequências danosas provocadas ao docente, cabendo citar, a título de exemplo, a não preparação metodológica e pedagógica do professor para lecionar através de novas tecnologias de informação e comunicação.

Será analisado também o acúmulo de atividades do docente, bem como a dúvida sobre a titularidade do direito patrimonial sobre os conteúdos produzidos pelo professor e o uso indiscriminado da obra pela instituição de ensino.

Por fim, serão apresentadas propostas dirigidas à regulamentação do ambiente laboral do ensino a distância, a fim de minimizar e, até mesmo, extinguir os principais agentes de precarização da atividade docente nessa modalidade de ensino.

Para desenvolver este estudo, fez-se um levantamento bibliográfico na área jurídica que envolveu o ambiente de trabalho no ensino a distância, não se circunscrevendo apenas a conteúdos jurídicos como também administrativos e econômicos, o que caracterizou o artigo como um estudo multidisciplinar. Apropriou-se do método dedutivo e ao final foram apresentadas propostas de proteção à referida modalidade de trabalho.

\section{AS NOVAS TECNOLOGIAS DE EMPREGADAS NO AMBIENTE DE TRABALHO DOCENTE DO ENSINO SUPERIOR A DISTÂNCIA E SUAS CONSEQUÊNCIAS}

A inserção das chamadas "novas tecnologias de informação e comunicação" acarretou também consequências danosas à atividade docente do ensino superior a distância no Brasil. Tal resultado foi devido ao seu uso inadequado, levando ao possível acúmulo de atividades bem como à exploração imprópria dos direitos autorais desse profissional. 
Em uma sociedade cada vez mais tecnológica deve-se reconhecer a necessidade em incluir nos currículos escolares habilidades para o manuseio de novas tecnologias, não podendo ser ignorado o elemento tecnológico na educação, por considerar que no emprego das novas tecnologias a quantidade de informações trocadas leva também à produção de conhecimento (MERCADO, 2002, p. 11).

Dessa maneira, não se pode negar o enriquecimento que a tecnologia trouxe e traz para a educação básica e superior, pois ela estende a busca pelo conhecimento além das salas de aula, bem como estreita a relação física e virtual entre professores e alunos (PARCIANELLO; KOZEN, 2016). Constata-se que a rede mundial de computadores gerou e impulsionou novas formas de interação e comunicação e, consequentemente, influenciou diretamente no ambiente de trabalho do professor e em suas práticas pedagógicas (RIBAS, 2008).

As novas tecnologias de informação e comunicação são as que mais estão presentes nas atividades comuns do cotidiano, de maneira direta ou indireta. $\mathrm{O}$ ambiente de ensino faz parte dessa realidade, afetando significativamente aqueles que dele se utilizam e ao mesmo tampo estão inseridos no contexto desse novo ambiente de trabalho (OLIVEIRA NETTO, 2010, p. 43), de maneira que esse profissional da educação precisa aprender a ser professor manuseando esses meios tecnológicos com uma pedagogia diferente, não se tratando apenas do uso do técnico dos recursos disponíveis, mas de seu uso pedagógico (LAPA; PRETTO, 2010).

Faz-se necessário, então, que alunos e professores possuam capacidade avaliativa e procedimental diante da variedade de recursos tecnológicos, principalmente os de informação e comunicação, tendo em vista que a celeridade de produção de novas tecnologias pede um aprendizado contínuo para utilizá-las (OLIVEIRA NETTO, 2010, p. 44).

Destarte, esse profissional da educação deve ter uma preparação técnica e pedagógica para lidar com as novas tecnologias de comunicação e informação em seu ambiente de trabalho, de maneira que sem o conhecimento técnico não será possível inserir ideias pedagógicas inovadoras, e sem o conhecimento pedagógico os recursos tecnológicos correm o risco de serem subutilizados (MELO; ANTUNES, 2002, p. 74).

Como não bastasse seu despreparo pedagógico, devido à mercantilização da educação, o docente é uma das tantas categorias atingidas pela tendência polivalente que o mercado exige, bem como pela invasão das novas tecnologias de comunicação e informação em seu ambiente de trabalho.

Além de despender tempo preparando aulas e para a atualização de seu conhecimento profissional, o professor precisa saber manusear aparatos tecnológicos para preparar suas aulas com a qualidade exigida pelo empregador (ALMEIDA, 2008, p. 79). Nesse sentido, a figura desse empregado polivalente, nas palavras de Almeida (2008), pode ser descrita da seguinte maneira: 
Esse predomínio de padrões flexíveis (toyotismo) produziu uma demanda para o desenvolvimento de habilidades cognitivas e comportamentais, supostamente capazes de garantir a empregabilidade. O trabalhador sob essa lógica deve ter a capacidade de: análise, síntese, estabelecimento de relações, rapidez de respostas e criatividade diante de situações desconhecidas, comunicação clara e precisa, interpretação e uso de diferentes formas de linguagem, capacidade para trabalhar em grupo, gerenciar processos, eleger prioridades, criticar respostas, avaliar procedimentos, resistir a pressões, enfrentar mudanças permanentes, aliar raciocínio lógico-formal à intuição criadora, estudar continuamente, e assim por diante (ALMEIDA, 2008, p. 79).

Posto isso, pode-se afirmar que é exigida do professor de ensino a distância uma qualificação maior do que o necessário para o exercício de sua função, já que além de sua especialidade docente é analisada sua habilidade no manuseio da tecnologia (ALMEIDA, 2008, p. 88).

Outra questão a ser discutida é sobre os direitos autorais dos professores conteudistas, pois em algumas instituições, os professores são instruídos a disponibilizarem o material escrito para os alunos acessarem a qualquer tempo, sem que ele tenha direitos sobre a aula por ele preparada (ALMEIDA, 2008, p. 87).

Os autores dos textos que servirão de base para a exposição das aulas são os professores conteudistas que, em sua grande maioria, são remunerados pelo trabalho intelectual desenvolvido somente uma única vez (WACHOWICZ, 2016), sendo que a utilização e principalmente a reprodução desse material ficará "eternizada" pela sua disponibilização na rede mundial de computadores.

No entanto, referente aos conteúdos elaborados para as aulas a distância, o que está em discussão é a disponibilidade dos direitos patrimoniais do docente sobre sua obra intelectual, tendo em vista que os direitos morais, inerentes à personalidade, são indisponíveis. Nesse âmbito, a situação do profissional da educação é claramente descrita nas palavras de Wachowicz (2016):

Inobstantemente, a proteção pelo Direito Autoral, denota-se uma fragilidade na relação jurídica que se estabelece entre o professor conteudista e a empresa de EAD, na medida em que, o conteúdo criado poderá ser replicado durante anos para milhares de pessoas, isto sem que o professor conteudista tenha participação econômica, ou ainda, sem que tenha condições de mensurar como se opera a utilização da sua criação visto que, muitas vezes nunca mais será contatado pela empresa de EAD. Tais questões são relevantes e devem estar previstas no contrato para perfeita tutela dos direitos autorais envolvidos na produção, distribuição e comercialização do material de EAD. 
Embora o professor autor possa dispor, por meio contratual, seus direitos patrimoniais apresentando cláusulas que abordam quanto ao uso, fruição, disponibilidade, cessão ou licença para a comercialização de sua obra, a legislação ainda é frágil no regramento dos direitos autorais dos docentes da modalidade ensino a distância (WACHOWICZ, 2016).

Sendo assim, conclui-se que é urgente a regulamentação dessa matéria, a fim de proteger os direitos que o professor tem sobre sua obra, bem como punir pessoas que usufruem indevidamente dela, evitando, dessa maneira, a precarização de seu digno trabalho.

\section{A PRECARIZAÇÃO ACARRETADA PELAS MUDANÇAS NO AMBIENTE DE TRABALHO DO DOCENTE DO ENSINO SUPERIOR A DISTÂNCIA}

Em que pese não existir regulamentação específica protegendo o docente do ensino superior a distância, a Magna Carta não deixou de contemplar a sua proteção, considerando que ainda sob o aspecto da sua eficácia contida, defende-se a aqui a sua plena eficácia.

A Constituição Brasileira (BRASIL, 1988) em seu artigo $7^{\circ}$, inciso XXVII, garantiu ao trabalhador a proteção em face da automação, com fundamento nos valores sociais do trabalho, pilares do Estado Democrático de Direito, e na dignidade da pessoa humana, considerada com uma das maiores finalidades da constituição (JOSÉ FILHO, 2016).

Considerando que o trabalho humano está elencado no rol de direitos e garantias fundamentais não se pode ignorar o caráter principiológico e impositivo de tais normas, de maneira que cabe ao Estado intervir na esfera econômica para que referidos direitos sejam efetivamente exercidos e contemplados (ALVES, 2016). O contido no inciso XXVII, artigo $7^{\circ}$, protege o trabalhador do desemprego acarretado pela automação, tendo em vista que o direito ao emprego é um bem jurídico tutelado pelo ordenamento brasileiro, bem como protege sua saúde física e mental pelo uso nocivo de tecnologias, visando um ambiente minimamente adequado (JOSÉ FILHO, 2016).

A automação não afetou somente o meio industrial, mas também o educacional, ambiente em que o professor dispõe de sua energia física e intelectual, tendo em vista que a educação não é pensada somente como direito de todos a fim formar cidadãos críticos, mas geralmente é vista como um serviço ou bem econômico que gera lucro (LAPA; PRETTO, 2010, p. 79-97).

No sistema de ensino a distância dentre os vários profissionais envolvidos em seu desenvolvimento, está o docente, que desenvolve e elabora os conteúdos a serem ministrados, e o tutor, que media a comunicação dos conteúdos entre professores e alunos (LAPA; PRETTO, 2010, p. 79-97).

Pode-se inferir, então, que o ambiente de trabalho virtual utilizado nessa modalidade de ensino acarretou, além do acúmulo e atividades, o desemprego e a precarização da atividade docente, tendo em vista o desvirtuamento das principais finalidades educacionais, que no caso, 
seriam a formar pessoas com pensamentos independentes e críticos e não somente gerar lucro.

O trabalho docente, principalmente na rede pública de ensino, também foi atingido pela instabilidade e insegurança presentes nas atuais relações trabalhistas, as quais podem ser observadas pela infraestrutura deficiente, recursos e materiais escassos e o aumento de contratos de trabalho temporários (MOURA, 2009).

Ademais, com a mercantilização da educação houve a necessidade de aumento do trabalho docente em qualidade, extensão e intensidade, pois do ponto de vista do capital, os professores precisam ser mais produtivos no que se refere a aulas, publicações, projetos e patentes. (BOSI, 2011).

Nesse contexto, aliado ao salário baixo, o professor se submete a uma rotina de trabalho demasiadamente carregada com a finalidade de proporcionar para si e sua família uma vida digna (MOURA, 2009). Na modalidade de ensino a distância não é diferente a situação dessa categoria de trabalhadores, tendo como exemplo o aumento da carga de trabalho e o "empobrecimento" do intermédio pedagógico por meio da atuação da tutoria (NEVES; FIDALGO, 2016).

É sabido que na modalidade de ensino a distância professores e alunos não possuem a experiência necessária para o uso das novas tecnologias de informação e comunicação, como também não há formação adequada dos docentes para manejar as metodologias de ensino por meio do ambiente virtual de trabalho (LAPA; PRETTO, 2010). Além disso, no Brasil a infraestrutura de comunicação de péssima qualidade como falta de equipamentos e velocidade de conexão baixa, o que dificulta a comunicabilidade de um ponto a outro (LAPA; PRETTO, 2010).

Como se pode observar, a modalidade de ensino a distância não é oferecida com o objetivo de democratizar a educação e facilitar o acesso a ela, e sim de gerar lucro utilizando a exploração da prestação de serviços de profissionais desvalorizados.

\section{PROPOSTAS DE APERFEIÇOAMENTO DA REGULAÇÃO DO AMBIENTE DE TRABALHO DO DOCENTE DO ENSINO SUPERIOR A DISTÂNCIA}

A Lei de Diretrizes e Bases da Educação nº. 9.394/96 traz em seu artigo 80 (BRASIL, 1996) os mecanismos de controle da modalidade de educação a distância e a indicação de quem pode oferecer esse serviço (MOURA, 2009).Todavia, não estabelece os parâmetros a serem seguidos na construção do ambiente de trabalho adequado para que o professor desenvolva suas aptidões profissionais no meio virtual.

Entretanto, o inciso VI do artigo 67 da mesma Lei expressa que os sistemas de ensino devem promover a valorização do professore lhe assegurar condições adequadas de trabalho (BRASIL, 1996).O Decreto ${ }^{0} 5.622$ de 19 de dezembro de 2015 que regulamenta o artigo 80 da Lei de Diretrizes e Bases da Educação, em seu inciso X, do artigo 12, expressa que as instituições que oferecem o ensino a distância deverão apresentar uma descrição detalhada dos serviços e suporte e infra-estruturas adequados para a realização do projeto pedagógico (BRASIL, 2015). 
Nesse contexto, para que a educação a distância seja fornecida são necessárias instalações físicas e tecnológicas apropriadas para que se tenha um ambiente de trabalho equilibrado para o docente exercer sua profissão com excelência.

Entretanto, não há legislação trabalhista e ou educacional regulando a relação laboral do docente do ensino a distância no sentido de dar tratamento às condições específicas dessa modalidade de trabalho. Por isso, infere-se que algumas matérias carecem de regulação como: o tempo à disposição do professor; repouso semanal; número de alunos por tutor virtual; local de trabalho; quantidade, extensão e tempo de avaliação das atividades desenvolvidas; forma de remuneração; direitos autorais; e despesas com equipamentos tecnológicos (BARROS, 2006).

Haja vista que a modalidade de ensino a distância tem cada vez maior adesão de interessados, não se pode ignorar a importância das consequências que ela trouxe aos trabalhadores que dela dependem, entre eles o professor. Por isso, Farias (2006) expõe algumas diretrizes para regulamentar as tarefas desse profissional:

1. elaboração de material deverá ser remunerada como hora-atividade já estabelecida na carga horária semanal do professor ou poderá se constituir em tarefa específica que deve ser previamente "negociada" com a instituição. Neste caso pode-se trabalhar como parâmetro o estabelecido no direito autoral;

2. para o acompanhamento aos alunos tanto na solução das dúvidas/ explicações complementares ou nos momentos de avaliação é necessário que este tempo seja estabelecido e remunerado pelo número de horasaula necessárias. Esta carga-horária deve estar integrada à carga horária semanal do professor ou a hora-aula deverá ter valores diferenciados, considerando-se o curso de curta duração;

3. gravação de vídeos: a remuneração poderá ser por hora-atividade ou por tarefa específica. Deve-se levar em conta, neste caso, o direito de imagem.

A Convenção Coletiva de Trabalho poderá ser um instrumento regulamentador do exercício dessa atividade, e Farias (2006) aponta questões que poderiam ser discutidas pela negociação coletiva:

- jornada de trabalho - jornada nuclear, previamente definida por contrato contrato por uma carga horária semanal, nos mesmos moldes e parâmetros;

- horário de trabalho - flexível, agenda de trabalho previamente definida com a instituição de ensino onde constariam datas/horários de presença do professor na instituição;

- comunicação - as formas de comunicação entre professor e instituição e professor e aluno devem se dar, preferencialmente, por correio eletrônico, pager, fax ou caixa postal telefônica; a comunicação não deve ser feita pelo telefone, seja residencial, seja pessoal do professor;

- direitos autorais - devem ser previamente estabelecidos pelas partes, no que 
Exemplificando, o Sindicato dos Professores do Rio Grande do Sul e o SINPRO/RS e o Sindicato dos Estabelecimentos de Ensino de 1 e 2 Graus - SINEPE/RS (2013) celebraram, a fim de regular a situação de seus professores do ensino básico, uma Convenção Coletiva de Trabalho que trouxe as seguintes cláusulas para modalidade de educação a distância:

\section{PROFESSORES DE EDUCAÇÃO A DISTÂNCIA}

Os estabelecimentos de ensino que ofertam cursos/disciplinas na forma "a distância" remunerarão os docentes que neles atuarem de acordo com as especificidades desta oferta, considerando a elaboração dos materiais, a docência propriamente dita e o atendimento aos alunos.

Parágrafo $1^{\circ}$ - Os equipamentos de multimídia utilizados pelos docentes na execução de planos de trabalho devidamente sintonizados com o plano pedagógico da instituição deverão ser por ela disponibilizados.

Parágrafo $2^{\circ}-\mathrm{O}$ atendimento aos alunos deverá ser, obrigatoriamente, no ambiente da instituição ofertante, sendo proibido o fornecimento para os alunos do telefone e email particular do professor.

Parágrafo $3^{\circ}-\mathrm{A}$ carga horária de trabalho do professor deverá ser previamente definida pela instituição de ensino.

Parágrafo $4^{\circ}-\mathrm{O}$ número de professores necessários para o desenvolvimento de um núcleo de trabalho e/ou de uma disciplina deverá ser previamente indicado, admitida, contudo, a sua variação, sempre que necessária para ajustar a oferta com a efetiva demanda.

Parágrafo $5^{\circ}$ - Não se inclui no âmbito definitório de "educação a distância" a simples disponibilização de material de apoio pedagógico no site da escola.

A Convenção Coletiva de Trabalho entre o Sindicato Dos Professores No Estado Do Paraná e o Sindicato Dos Estabelecimentos Particulares De Ensino Do Estado Do Paraná (2015), por exemplo, abordou de maneira geral sobre uso da imagem do professor e dos produtos por ele produzidos:

Parágrafo oitavo: Nas contratações que envolvam uso de imagem e nome do professor, tal como, exemplificativamente, ocorre nas aulas gravadas, deverá ser estipulado em contrato o licenciamento respectivo, contendo prazo de duração, valores pagos (caso este tenha ocorrido a título oneroso), bem como a propriedade de eventuais produtos confeccionados e a titularidade dos direitos de exploração (SINDICATO DOS PROFESSORES NO ESTADO DO PARANÁ; SINDICATO DOS ESTABELECIMENTOS PARTICULARES DE ENSINO DO ESTADO DO PARANÁ, 2015). 
Entretanto, as cláusulas de convenções, acordos ou contratos entre o professor empregado e empregador não são suficientes para regrar essa relação de emprego. É preciso o agir do Poder Legislativo, que até o presente momento foi omisso em relação à matéria. Sobre a ineficiência do poder público em regulamentar o trabalho dos professores tanto do ensino presencial quanto os do ensino a distância, Prado e Prado (2013) esclarecem que:

Essa "desregulamentação", fruto da descentralização do poder regulamentar em matéria de Educação que foi conferido à União, Estados, Distrito Federal e Municípios pela LDB, contribui sobremaneira para a precarização das relações de trabalho dos professores, sobretudo no que diz respeito à delimitação do tempo que lhes é garantido por lei para os estudos, planejamento, avaliação, pesquisa e extensão.[...] sendo o professor um agente transformador da sociedade e, portanto, um agente político, consequentemente, a regulamentação do seu regime de trabalho desafia uma normatização que observe as especificidades da carreira, sobretudo no que diz respeito à carga horária de trabalho. [...] A fim de estabelecer condições adequadas de trabalho aos docentes, as políticas públicas implementadas no Brasil, notadamente a partir da LDB de 1996, têm se mostrado ineficientes, à medida que lidam com a matéria sem tratar minuciosamente das condições mínimas para que o professor realize satisfatoriamente a atividade educacional e, dentre elas a regulamentação da divisão justa da carga horária de trabalho do docente.

Tendo em vista a falta de legislação específica, deve-se recorrer aos princípios norteadores do Direito do Trabalho e do Direito Ambiental do Trabalho (SCOTTINI, 2012), por isso, observar o princípio do meio ambiente de trabalho equilibrado no momento de elaboração das normas trabalhistas é essencial para melhorar a qualidade de vida do docente em seu meio laboral.

O princípio da proteção ao trabalhador, na falta de normas e regulamentação específicas, também deve ser aplicado para nortear as condições de trabalho do professor do ensino à distância, a fim de evitar a sua precarização, visto que é a razão da existência do Direito do Trabalho, de maneira que a proteção é o que dá legitimidade à regra trabalhista (SEVERO, 2013).

Assim como os princípios do ambiente de trabalho equilibrado e o da proteção, outros dois importantes princípios para a elaboração de tais normas regulamentadoras são o da precaução e o da prevenção, já que para evitar danos ao docente e a precarização de sua atividade profissional é necessário agir antecipadamente.

É notória, então, a urgência em regular o trabalho docente na modalidade de ensino a distância, pois as condições em que esse profissional é exposto para desempenhar suas atividades, principalmente no tocante ao seu regime de trabalho, estão diretamente ligadas à qualidade de ensino que será ofertado e, inevitavelmente, atingirá de maneira positiva ou negativa a finalidade libertadora e emancipadora que a educação se propõe (PRADO; PRADO, 2013).

Por fim, não se pode ignorar a delicada situação em que encontra tal trabalhador, sendo necessário dar ouvidos a essa categoria trabalhista a fim de minimizar e, quiçá, extinguir os danos 
que a inserção de novas tecnologias em seu ambiente laboral possa acarretar.

\section{CONCLUSÃO}

A inserção das novas tecnologias da informação e comunicação no ambiente de trabalho docente possibilitou uma maior interatividade entre aluno e professor, facilitando a troca de dados e conhecimento, principalmente na atual modalidade de ensino a distância, pois nesse caso as aulas são ministradas virtualmente.

Embora a internet, as tecnologias informáticas, microeletrônicas e de telecomunicações tenham enriquecido a educação básica e superior com o estreitamento entre aluno e professor independentemente do espaço físico, trouxeram também consequências não vantajosas ao professor em si, precarizando o trabalho docente.

Dentre tais decorrências, está a não formação pedagógica dos professores sobre as novas metodologias de ensino por meio das novas tecnologias de informação e comunicação, sendo necessário um processo didático e metodológico diferenciado para a formação adequada do aluno.

O acúmulo de atividades é outra consequência que precariza o trabalho docente, pois o atual mercado de trabalho exige empregados multifuncionais ou polivalentes, não sendo diferente com essa categoria de trabalhador, acarretando a intensificação e novas cargas de trabalho, bem como a incidência do estresse.

Dessa maneira, as instituições de ensino exigem dedicação exagerada desse trabalhador sem o devido reconhecimento e valorização, pois o professor da modalidade do ensino a distância além de despender de seu tempo preparando aulas, deve saber manusear aparatos tecnológicos para ministrar suas aulas, ter comunicação clara e precisa, rapidez de reposta e criatividade em situações desconhecidas, intuição criadora entre outras exigências.

A dúvida sobre a titularidade do direito patrimonial sobre autoria dos conteúdos elaborados pelo professor do ensino à distância e seu uso indiscriminado também precariza o trabalho docente. Melhor explicando, tendo em vista que o conteúdo intelectual foi produzido sob uma relação de emprego, não se sabe se o direito de usufruir patrimonialmente da obra e o do autor empregado ou a da instituição de ensino empregadora.

Há quem diga que o contrato de trabalho firmado entre as partes é que indicará o titular desse direito. No entanto, é sabido que o conteúdo criado pelo professor e disponibilizado na internet poderá ser utilizado por anos e compartilhado por milhares de pessoas, sem que seu autor tenha a devida participação econômica sobre a obra.

Destarte, a fim de se evitar a precarização do trabalho docente do ensino a distância, deve haver a efetiva proteção normativa em face da automação, para que o uso de novas tecnologias inseridas no ambiente de trabalho do professor não seja nocivo à qualidade de vida desse trabalhador e tampouco diminua a mão de obra docente.

Embora ainda não exista regulamentação adequada e específica para a proteção da docência do ensino superior a distância, cabe aos Tribunais pátrios, enquanto órgãos por excelência na 
aplicação do direito, no momento de solucionar os litígios entre professor empregado e instituição de ensino empregadora, aplicar os princípios norteadores do Direito do Trabalho e do Direito Ambiental do Trabalho, a fim de minimizar os efeitos que a precarização acarreta a esse trabalhador.

\section{REFERÊNCIAS}

ALMEIDA, Sérgio Antunes. Novas tecnologias e o trabalho docente na modalidade ensino a distância. 2008. 143 f. Dissertação (Mestrado em Ciências Sociais) - Universidade Estadual de Londrina, Londrina, 2008.

ALVES, Fonseca Henrique. Proteção em face da automação e a eficácia dos direitos fundamentais. Disponível em: <http://revistaadmmade.estacio.br/index.php/ direitobh/article/ viewFile/259/164>. Acesso em: 16 mar. 2016.

BARROS, Veronica Altef. O trabalho docente virtual: análise jurídica das condições de trabalho decorrentes do sistema de educação a distância. In: CONPEDI, 15., 2006, Manaus. Anais... Manaus, 2006. Disponível em: <http://publicadireito.com.br/conpedi/manaus/ arquivos/anais/bh/ veronica_altef_barros.pdf>Acesso em: 17 maio 2016.

BOSI, Antônio de Pádua. Precarização e intensificação do trabalho no Brasil recente: ensaios sobre o mundo dos trabalhadores (1980-2000). Cascavel: Edunioeste, 2011.

BRASIL. Constituição (1988). Constituição da República Federativa do Brasil. Disponível em: <http://www.planalto.gov.br/ccivil_03/constituicao/ConstituicaoCompilado.htm>. Acesso em: 12 jan. 2016.

BRASIL. Decreto $\mathbf{n}^{0} 5.622$ de 19 de dezembro de 2015. Regulamenta o art. 80 da Lei no 9.394, de 20 de dezembro de 1996, que estabelece as diretrizes e bases da educação nacional. Disponível em: <http://www.planalto.gov.br/ccivil_03/_ato2004-2006/2005/decreto/d5622. htm>. Acesso em: 31 mar. 2016.

BRASIL. Lei $\mathbf{n}^{0}$ 9.394, de 20 de dezembro de 1996. Estabelece as diretrizes e bases da educação nacional. Disponível em: <http://www.planalto.gov.br/ccivil_03/leis/L9394.htm>. Acesso em: 31 mar. 2016.

FARIAS, Cecília. Há um fosso entre o ideal e real na EAD no Brasil. In: SINPROSP. Avaliação crítica da educação a distância. 2006. p. 19-22. Disponível em: <http://www.sinprosp.org.br/ arquivos/ead/folheto_ead_22maio.pdf $>$. Acesso em: 3 maio 2016.

JOSÉ FILHO, Wagson Lindolfo. A eficácia do direito fundamental da proteção em face da automação previsto no inciso XXVII, do art. $7^{\circ}$, da Constituição Federal de 1988. Revista Jus Navigandi, Teresina, ano 21, n. 4820, 11 set. 2016. Disponível em: <https://jus.com.br/ artigos/35702/a-eficacia-do-direito-fundamental-da-protecao-em-face-da-automacao-previsto-noinciso-xxvii-do-art-7-da-constituicao-federal-de-1988>. Acesso em: 14 mar. 2016.

LAPA, Andrea; PRETTO, Nelson de Luca. Educação a distância e precarização do trabalho docente. Em Aberto, Brasília, v. 23, n. 84, p. 79-97, nov. 2010. Disponível em: <https:// repositorio.ufba.br/ri/bitstream/ri/5569/1/1792-7441-1-PB.pdf $>$. Acesso em: 21 mar. 2016. 
MELO, Manoel Messias Moreira; ANTUNES, Márcia Cristina Tenório. Software livre na educação. In: MERCADO, Luís Paulo Leopoldo. Novas tecnologias na educação: reflexões sobre a prática. Maceió: UFAL, 2002.

MERCADO, Luís Leopoldo. Formação docente e novas tecnologias. In: MERCADO, Luís Paulo Leopoldo (Org.). Novas tecnologias na educação: reflexões sobre a prática. Maceió: UFAL, 2002.

MOURA, Ingrid Louback de Castro. A automatização da educação: o telensino e a precarização do trabalho docente. 2009. 122 f. Dissertação (Mestrado em Educação) - Universidade Federal do Ceará, Fortaleza, 2009. Disponível em: <http://www.repositorio.ufc.br/bitstream/ riufc/3131/1/2007_Dis_ILCMoura.pdf $>$. Acesso em: 29 mar. 2016.

NEVES, Viana de Salles Inajara; FIDALGO, Fernando Selmar. Docente virtual na educação a distância: condições de trabalho na rede privada de ensino. Disponível em: $<$ http://www.senept. cefetmg.br/galerias/Arquivos_senept/anais/quarta_tema3/QuartaTema3Artigo7.pdf>. Acesso em: 29 mar. 2016.

OLIVEIRA NETTO, Alvim Antônio de. IHC e a engenharia pedagógica. Florianópolis: Visual Boooks, 2010.

PARCIANELLO, Leudemila; KOZEN, Paulo Cezar. Docência no ensino superior: o uso das novas tecnologias na formação de professores na licenciatura. Disponível em: <http://www. arcos.org.br/artigos/docencia-no-ensino-superior-o-uso-das-novas-tecnologias-na-formacao-deprofessores-na-licenciatura/\#topo>. Acesso em: 10 fev. 2016.

PRADO, Ricardo Antônio Nunes; PRADO, Mariana Siqueira. A precarização das relações de trabalho do professor em face da regulamentação do trabalho docente no Brasil. In: SIMPÓSIO DA ANPAE, 26., 2013, Recife. Anais... Recife, 2013. Disponível em: <http://www.anpae.org.br/ simposio26/1 comunicacoes/RicardoAugustoNunesPrado-ComunicacaoOral-int.pdf $>$. Acesso em: 20 maio 2016.

RIBAS, Daniel. A docência do ensino superior e as novas tecnologias. Revista Eletrônica Lato Sensu, Guarapuava, ano 3, n. 1, mar. 2008. Disponível em: <file://C:/Users/Note/ Downloads/A\%20docncia\%20superior\%20e\%20as\%20novas\%20TICs.pdf $>$. Acesso em: 23 fev. 2016.

SCOTINNI, Debora Tiemi. Aspectos trabalhistas na educação a distância. Conteúdo Jurídico, Brasília, 27 abr. 2012. Disponível em: < http://www.conteudojuridico.com.br/artigo,aspectostrabalhistas-na-educacao-a-distancia,36572.html>. Acesso em: 20 maio 2016.

SEVERO, Valdete Souto. Princípio da proteção do trabalhador. Revista Jus Navigandi, Teresina, ano 18, n. 3633, 12 jun. 2013. Disponível em: <https://jus.com.br/artigos/24690>. Acesso em: 21 maio 2016.

SINDICATO DOS PROFESSORES DO RIO GRANDE DO SUL; SINDICATO DOS ESTABELECIMENTOS DE ENSINO DE 1 E 2 GRAUS. Convenção Coletiva de Trabalho 2013/2014 n' RS000815/2013, de 24 de maio de 2013. Disponível em: <http://www.sinprors.org. $\mathrm{br} /$ convencoes/pdf/conven_basico.pdf $>$. Acesso em: 19 maio 2016.

SINDICATO DOS PROFESSORES NO ESTADO DO PARANÁ; SINDICATO DOS 
ESTABELECIMENTOS PARTICULARES DE ENSINO DO ESTADO DO PARANÁ.

Convenção Coletiva de Trabalho 2015/2016 n PR002752/2015, de 9 de julho de 2015.

Disponível em: <http://www.pucpr.br/arquivosUpload/5379512971452883784.pdf > . Acesso em: 20 maio 2016.

WACHOWICZ, Marcos. Ensino a distância e direitos autorais: a produção do conhecimento e sua tutela jurídica. Disponível em: <http://gedai.com.br/sites/default/files/arquivos/artigo_ direito_autoral_ead_0.pdf>.Acesso em: 3 maio 2016.

Como citar: OLIVEIRA, Lourival José de; ALMEIDA, Tamires Souza de. A precarização do trabalho docente: análise crítica das alterações no ambiente de trabalho produzidas no ensino superior a distância. Revista do Direito Público, Londrina, v. 13, n. 3, p. 10-23, dez. 2018. DOI: 10.5433/24157-108104-1.2018v13n3 p. 10. ISSN: 1980-511X.

Recebido em: 22/09/2016

Aprovado em: 22/11/2018 